\title{
Trust and the Manager-Subordinate Dyad: Virtual Work as a Unique Context
}

\author{
Karen Moustafa-Leonard \\ Indiana University-Purdue University Fort Wayne
}

\begin{abstract}
Despite the importance of manager trust in subordinates, little has been done to examine the role of managers' trust in subordinates, although a great deal of research has been done concerning ways to induce employees' trust in their managers and organizations. In this paper, the mechanisms of managerial development of trust in virtual work are outlined, as a unique context, and an attempt is made to define some of the potential moderators. Management trust development is conceptualized in a framework, and implications for future research and practice are identified. It may be that improving measurement of virtual work will improve the linkages leading to trust in the dyad, particularly managers' trust in subordinates.
\end{abstract}

\section{Trust and Organizational Behavior Research}

It is evident that trust between organizational members allows coordination and completion of work. Not only do employees need to have trust in the organization, the manager, and their peers, but the manager must trust the subordinates for whom he or she is responsible. Despite the importance of manager trust in subordinates, little has been done to examine the role of managers' trust in subordinates, although some papers on topics such as e-leadership (Cascio \& Shurygailo, 2002) and overall relationship influences (Dambrin, 2004) are beginning to surface. Little work has been done on this latter aspect of the relationship, Most work to date has focused on inducing employees' trust in their managers and organizations (for example, Connell \& Ferres, 2003; Thoms, Dose, \& Scott, 2002).

This paper examines the relationship of trust of managers in their subordinates who work and communicate primarily through use of computers (i.e., subordinates who do not generally communicate with their managers through face-to-face encounters), rather than those who spend a day or two a week away from the manager. The subordinates we discuss may be only a short walk away from the manager on another floor of the same building, or they may work in another location in the city, state, country, or even across national boundaries. Formerly, these individuals were called teleworkers, but the new paradigm labels them "virtual workers" (Cascio \& Shurygailo, 2002).

With increasing technological improvements, virtual workers are becoming more commonplace (Cascio \& Shurygailo, 2002; Gerke, 2006; Illegems \& Verbeke, 2004; Taylor \& Kavanaugh, 2005). In these cases, the development of manager-subordinate dyad trust is more difficult because there is little or no face-to-face interaction, creating risk and uncertainty as cornerstones of this dyadic relationship. As we will discuss, risk and uncertainty combat development of trust. 
In this paper, the mechanisms of managerial development of trust in virtual work are outlined, as a unique context, and an attempt is made to define some of the potential moderators. Management trust development is conceptualized in a framework, and implications for future research and practice are identified.

\section{Development of Trust}

Research on trust in organizational contexts is fairly new (Kramer \& Tyler, 1996; Mayer, Davis, \& Schoorman, 1995; Sitkin \& Roth, 1993; Lewicki, McAllister, \& Bies, 1998). Trust has been described as not only being able to predict another's behavior through past experience (Deutsch, 1958), but also as having confidence in this prediction, even when faced with risk (Lewis \& Weigert, 1985; Mayer, Davis, \& Schoorman, 1995). Boon and Holmes (1991) define trust as:

A state involving confident positive expectations about another's motives with respect to oneself in situations entailing risk (p. 194).

Trust often consists of predictability, dependability, and faith between partners (Rempel, Holmes, \& Zanna, 1985; Drucker, 1990). If it were possible to have complete knowledge of an individual, then trust would not be needed (Simml, 1964).

Trust is the framework upon which any relationship is build (Blau, 1964; Rempel, Holmes, \& Zanna, 1985; Zand, 1972). Individuals have expectations of others which, when met, develops into trust (Robinson, 1996). People depend upon others to exhibit goodwill, sympathy, and appropriate social conduct in routine settings (Rempel, Holmes, \& Zanna, 1985). Appropriate and relatively eqal exchanges of social capital are the key to trust development (Arrow, 1974; Reed, 1991). Social capital is a quality created among individuals (Bourdieu \& Wacquant, 1992; Burt, 1992; Coleman, 1988, 1990; Lin, 1998) through the exchange of goods, services, money, information, status, and love (Foa \& Foa, 1974).

As outlined by Foa and Foa (1974), appropriate exchanges are those in which socially correct reciprocity occurs. Each culture (both societal and organizational) sets up its own norms of reciprocity that are reasonably stable, and this reciprocity is the mechanism that facilitates the development of trust over time (Gouldern, 1973). For example, in Western societies, exchanging money for goods and/or services is socially acceptable, but exchanging money for information or status is less appropriate. At the far extreme, exchanges of money for love are not acceptable. Therefore, unequal or unacceptable exchanges of social capital, as determined by the cultural context, can inhibit the development of trust. Trust grows and develops as these exchanges occur during different interacts over time (Lewicki, McAllister, \& Bies, 1998). Lewis and Weigert (1985) and McAllister (1995) identified two components of trust: cognitive and affective. Cognitive trust is based on evidence of trustworthiness, 
enabling an individual to decide whether to give or withhold trust. Affective trust is a deep emotional attachment during a relationship.

Some individuals are more willing to exhibit trust on very little evidence of trustworthiness in the other individual, while others require a great deal of evidence before they exhibit trust (Lewicki, et.al., 1998). This propensity to trust has been identified by some researchers as a personality trait, originating in early development (Worchel, 1979). Therefore, propensity to trust could determine the level of trust generated in the early exchanges of social capital. This has effects in the relationship generating trust between managers and subordinates.

\section{Trust in the Manager-Subordinate Dyad}

Trust develops because of the individual's propensity to trust, combined with appropriate and relatively equal exchanges of social capital over time. In the case of the manager-subordinate dyad, the subordinate exchanges services (performance) for money (wages). If the manager determines that the subordinate is not earning the money paid for services (e.g., the subordinate performs poorly), then an unequal exchange is seen to take place by the manager, reducing the manager's trust in the subordinate.

McGregor (1967) defined managers as one of two types: Theory $X$ managers, who do not trust their subordinates, and Theory $Y$ managers, who trust their subordinates. Theory $Y$ involves the delegation of decision-making to the subordinate, which requires the manager take a risk that the subordinate will perform appropriately (Costigan, Ilter, \& Berman, 1998). Most individuals prefer to deal with those they know or with those they have dealt with before (Granovetter, 1985). However, when selecting new or current staff members to provide virtual services, managers must rely on reported or observed past performance to judge how must trust to give to the virtual worker.

Defining, facilitating, and encouraging performance are fundamental managerial tasks essential to appropriately supervising subordinates, including virtual workers (Cascio, 2000; Cascio \& Shurygailo, 2002; Knights, Noble, Vurdubakis, \& Willmott, 2001). In cases where task performance is not well defined, monitored, and/or measured, trust is necessarily lower than for employees viewed routinely. When subordinates spend most of their time at a physical distance from the manager, trust is crucial for relationship maintenance. Otherwise, control of the work becomes a problem if there is a lack of trust within the manager-subordinate dyad (Knights, et.al., 2001). McAllister (1995) examined trust in a selection of peers and found that affective trust is positively correlated with monitoring of performance. In other words, performance is closely tied to trust in workplace contexts, at least among colleagues. It is not a huge leap to postulate that trust and performance are closely aligned in the manager-subordinate dyad. This is visualized in Figure 1. 


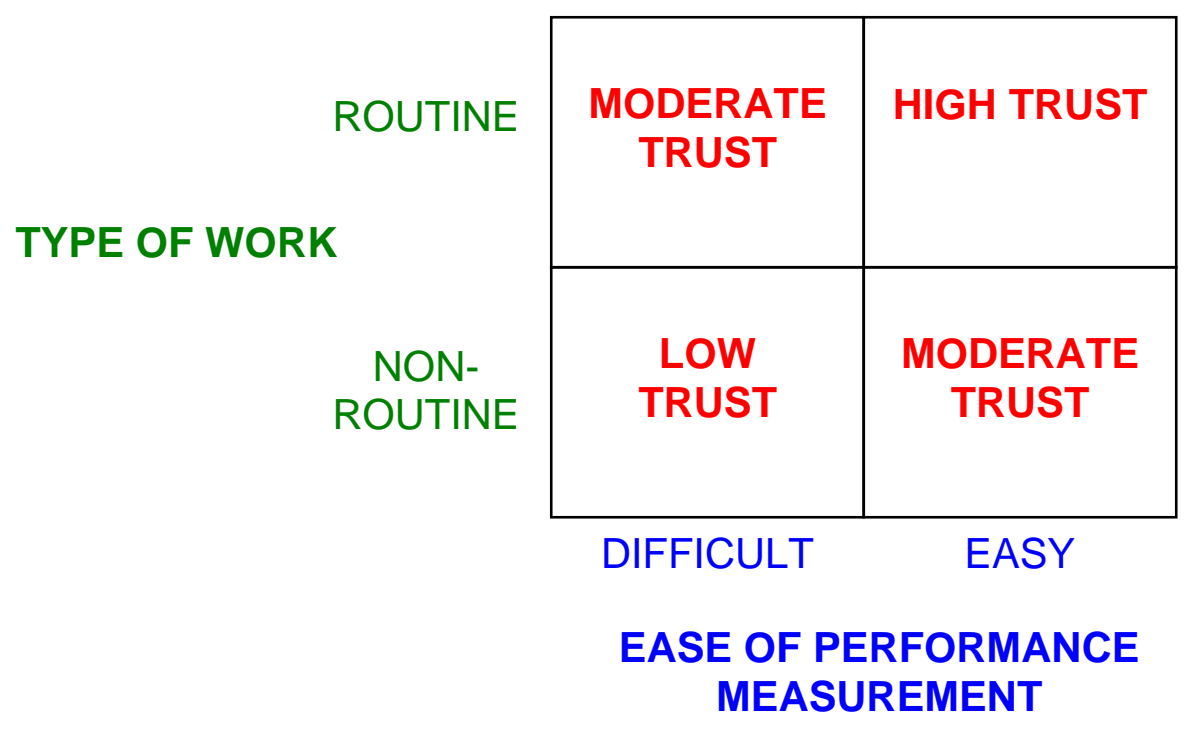

Figure 1. Relationship of measurement and type of work to potential levels of trust

It is likely that trust is likely to be found in either routine or non-routine work, depending a great deal on the ability of the manager to measure performance or output. This becomes more difficult when the manager has virtual workers and can no longer judge performance simply by seeing whether the worker is present and looks busy (DiMartino \& Wirth, 1990). Where jobs are routine and can be closely measured and monitored (e.g., typists), trust will range from moderate to high (El Sawy, 1985; Jarvenpaa, Knoll, \& Leidner, 1998).

\section{References}

Cascio, W. F. \& Shurygailo, S. (2003). E-leadership and virtual teams. Organizational Dynamics, 31 (4): 362-376.

Connell, J. \& Ferres, N. (2003). Engendering trust in manager-subordinate relationships: Predictors and outcomes. Personnel Review, 32 (5): 569-673.

Dambrin, C. (2004). How does telework influence the manager-employee relationship. International Journal of Human Resources Development and Management, 4 (4): 358374.

Gerke, S. K. (2006). If I cannot see them, how can I lead them? Industrial and Commercial Training, 38 (2): 102-105.

Horwitz, F. M., Bravington, D. \& Silvis, U. (2006). The promise of virtual teams: Identifying key factors in effectiveness and failure. Journal of European Industrial Training, 30 (6): 472-494. 
Illegems, V. \& Verbeke, A. (2004). Telework: What does it mean for management? Long Range Planning, 37: 319-334.

Panteli, N. \& Duncan, E. (2004). Trust and temporary virtual teams: Alternative explanations and dramaturgical relationships. Information Technology \& People, 17 (4): 423-441.

Taylor, D. S. \& Kavanaugh, J. K. (2003). Paradigms of leadership in the teleworking environment: A qualitative study. Proceedings of the Academy of Organizatinoal Culture, Communications and Conflict, 10 (1): 57-61.

Thoms, P., Dose, J. J. \& Scott, K.S. (2002). Relationships between accountability, job satisfaction, and trust. Human Resource Development Quarterly, 13 (3): 307-323. 